\title{
Mobile Road Traffic Management System Using Weighted Sensors
}

\author{
https://doi.org/10.3991/ijim.v11i5.6745 \\ Akinboro S.A. $\left.{ }^{\square}\right)$, Adeyiga J.A. \\ Department of Computer Science and Information Technology, \\ Bells University of Technology, Ota, Ogun State, Nigeria. \\ akinboro2002@yahoo.com \\ Omotosho A. \\ Landmark University, Omu-Aran, Kwara State, Nigeria.
}

Akinwumi A.O.

Bowen University Iwo, Osun State, Nigeria

\begin{abstract}
Vehicular traffic is continuously increasing around the world, especially in urban areas, and the resulting congestion has become a major concern to automobile users. The popular static electric traffic light controlling system can no longer sufficiently manage the traffic volume in large cities where real time traffic control is paramount to deciding best route. The proposed mobile traffic management system provides users with traffic information on congested roads using weighted sensors. A prototype of the system was implemented using Java SE Development Kit 8 and Google map. The model was simulated and the performance was assessed using response time, delay and throughput. Results showed that, mobile devices are capable of assisting road users' in faster decision making by providing real-time traffic information and recommending alternative routes.
\end{abstract}

Keywords-Congestion, Traffic Control, Mobile Devices, Smart Phones, road users.

\section{Introduction}

Traffic management system is the planning, monitoring, control and influencing the volume of traffic [1]. The objectives of traffic management is to maximize the effectiveness of the use of existing infrastructure, ensure reliable and safe operation of transport, address environmental goals and ensure fair allocation of infrastructure space (e.g. road space) among competing users [1].

Basically two approaches can be applied in order to minimize transportation problems [2]. The most straight forward solution is to build more infrastructures, such as bridges, roads and viaducts, in order to increase capacity but this is not sufficient. Constructing new road infrastructure is limited due to environmental, social and financial constraints. The present traffic solutions in the urban areas such as traffic 
light have caused road users to stay longer than necessary on the road, resulting to increase in the cost of transportation, failure of appointments and health problems as a result of $\mathrm{CO}_{2}$ emissions [3].

This research presents a scalable, integrated traffic management solution that enables mitigation of traffic congestion. The traffic management solution was developed using mobile devices and weighted sensors. The system was able to provide real time traffic information to road users on their mobile devices and also suggests alternative routes. This will provide road users with relevant traffic information needed to make intelligent decisions for a safe, faster and convenient trip.

\section{Related Work}

There are several research works on transport management system especially in the area of traffic control. Some of the existing works for various traffic control system were reviewed in order to identify the research description. In [4], an intelligent transportation system ITS services using cloud computing was presented. Identifying information (such as driver personal identification) transmitted by the sensor was secured through a proposed Vehicular Cloud Computing Service-oriented Security Framework (VCC-SSF) to address the limitations and security threats of VCC-based services. The work majorly focused on securing important data transmitted via the network. Also, [5] proposed an Unmanned Aerial Vehicles (UAVs), as a mobile sensor to collect road traffic information. Cruise route planning problem of UAVs was developed based on the highway network physical structure and a multi-objective optimization model was proposed to minimize both the total cruise time and the information value non detected by UAVs. Finally, a case study was used to demonstrate the results of the proposed model in UAVs' route planning.

In the work done by [6], a system that was able to calculate vehicle's weight at any moment was proposed. The system was capable of measuring changes of vehicle suspension system in order to monitor changes of vehicle loading weight in various local and time situations and also, checking driver's attitude toward road surface roughness. The functionalities include, tracking mobile vehicle and showing them on maps inside the control center which can also be an intelligent tracking via a telegraphic that connects between mobile vehicles and the control center. Therefore, monitoring the situation such as; exact location, speed, other information regarding each vehicle, ability to send and receive message, control on sensors and to restrict the vehicles activities based on some defined rules such as forbidden areas, areas under inspection.

In the effort of [7], IEEE 802.15.4 network architecture was used to monitor vehicular traffic flows near to a traffic light. The architecture was implemented with an innovative algorithm in order to determine green times and phase sequence of traffic lights, based on measured values of traffic flows. The focus of their work was to reduce the average waiting time. Several simulations were performed to confirm the validity of the proposed approach and the obtained results illustrated that, it is possible to obtain a better management of isolated traffic light junctions. According to [8] 
it was discovered that in a conventional traffic light controller, the traffic lights change at fixed time. This is because many traffic light controllers implemented in current practice, are based on the 'time-of-the-day' scheme which uses a limited number of predetermined traffic light patterns and implement these patterns depending upon the time of the day. They concluded that this automated systems do not provide an optimal control for fluctuating traffic volumes. They then emphasized that the efficiency of traffic flow through an intersection depends on the phases, sequence and the timing of the traffic signals installed to minimize the wait time of the vehicle in each queue. So, the fuzzy optimization used in their work deals with finding the values of input parameters of a complex simulated system which results in desired output. Fuzzy logic controller is then used to execute fuzzy logic inference rules from a fuzzy rule base in determining the congestion parameters, getting the warning information and the appropriate action. The number of vehicles in each lane is measured using sensors and at the end of each phase these numbers are used as inputs to fuzzy controller. Fuzzy controller calculates the duration of green light as per the traffic situation. Their simulation results show an improvement in the overall outcome of traffic management as compared to the conventional traffic controller, marking great feasibility and practicality of their model.

The work of [9] also proposed the use of wireless sensor networks to sense the presence of traffic near junctions and route the traffic based on traffic density in the desired direction with a microcontroller based routing algorithm. The sensors interact with the physical environment while the transmitter pages the sensor's data to the central controller which then receives the signal and computes the road and lane that has to be given green signal based on the density of traffic. The controller uses routing algorithm to perform the intelligent traffic routing. This is very easy to implement, less expensive. In [10] a similar method to that of [9] was presented, to avoid pedestrians coming in contact with heavy traffic rather than just sensing the presence of traffic near junctions. The work of [11] designed a system that utilizes and efficiently manages traffic light controllers. The work described an adaptive traffic control system based on an improved traffic infrastructure using Wireless Sensor Network (WSN). This was found to be dynamically adaptive to traffic conditions on both single and multiple intersections. The system design supported traffic control over multiple intersections and followed international standards for traffic light operations. In addition, a central monitoring station was designed to monitor all access nodes. Likewise, the traffic lights controller was designed with a priority queue to store all the requests. Emergency vehicles in different directions are stored in queue. They are allowed according to their priority along their directions. Traffic lights controller is responsible to check priority and change lights accordingly.

The authors in [3] worked on the cooperation of vehicles (nodes) on the network through the use of forward manager and fuzzy reputation manager to improve the overall performance of a vehicular ad hoc network by encouraging packet forwarding. The forward manager in each node keeps track of the number of received forwarding requests and the number of packets which have been forwarded so far. The fuzzy reputation manager checks each packet's source node to see whether it is selfish or not. Packets that belong to selfish source nodes are eliminated from the network. 
Their simulation results showed that the proposed scheme can successfully increase network performance. Niittymaki in [12] presented a field test of a simple two-phase fuzzy signal controller. The results showed that the fuzzy logic controller performed better than vehicle-actuated control in terms of delay, percentage stops and savings in fuel and emissions. The efforts of [13] considered the arriving rates of compared signals based on a fuzzy rule approach which was designed to regulate traffic flow for oversaturated intersections. The fuzzy controller decides whether to terminate the currently green signal or extends it for some period. The assessments were made using set of fuzzy rules. These rules considered the queuing lengths and arrival rates of current green signal and then compare these to the waiting signal.

In [14] an intelligent RFID traffic control in order to solve the problems with system that uses image processing and beam interruption techniques was developed. In their work, RFID technology with appropriate algorithm and database were applied to a multi vehicle, multi-lane and multi road junction area to provide an efficient time management scheme. The simulation results from the work shows that the dynamic sequence algorithm has the ability to intelligently adjust itself even with the presence of some extreme cases. The real time operation of the system emulated the judgment of a traffic policeman. The authors in [15] developed a real time traffic signal timing model which was integrated into a single intersection for urban road to solve the problem of traffic congestion. The method employed was to first analyze the current situation of the traffic flow and then put forward the basic models to minimize total delay time of vehicles at the intersection. Their result provided useful insight on signal control to prevent traffic congestion. Also authors in [16] developed an intelligent traffic light control using fuzzy logic which has the capability of mimicking human intelligence for controlling traffic lights. The time delay experienced by the vehicles using the fixed as well as fuzzy traffic controller is then compared to observe the effectiveness of the fuzzy traffic controller. As it can be deduced from the review, several different techniques have been proposed for ameliorating vehicular traffic, most of which are either not mobile or road users centered. This work adapted and improved on [8] to propose a mobile traffic management system using weighted sensor to provide real time traffic information to road users on their mobile devices and also suggest alternative routes.

\section{Materials and Method}

\subsection{Architecture for the Mobile Traffic Management System}

The proposed architecture in Figure 1 consists of weighted sensors, global positioning system, VSAT, control room and mobile devices. It illustrates how information from the sensors on the road get to the control room and are being display through Google map on the mobile devices. Road users will be alerted on their mobile devices to know the traffic status and will be provided with alternative routes to take when a certain area is congested. 


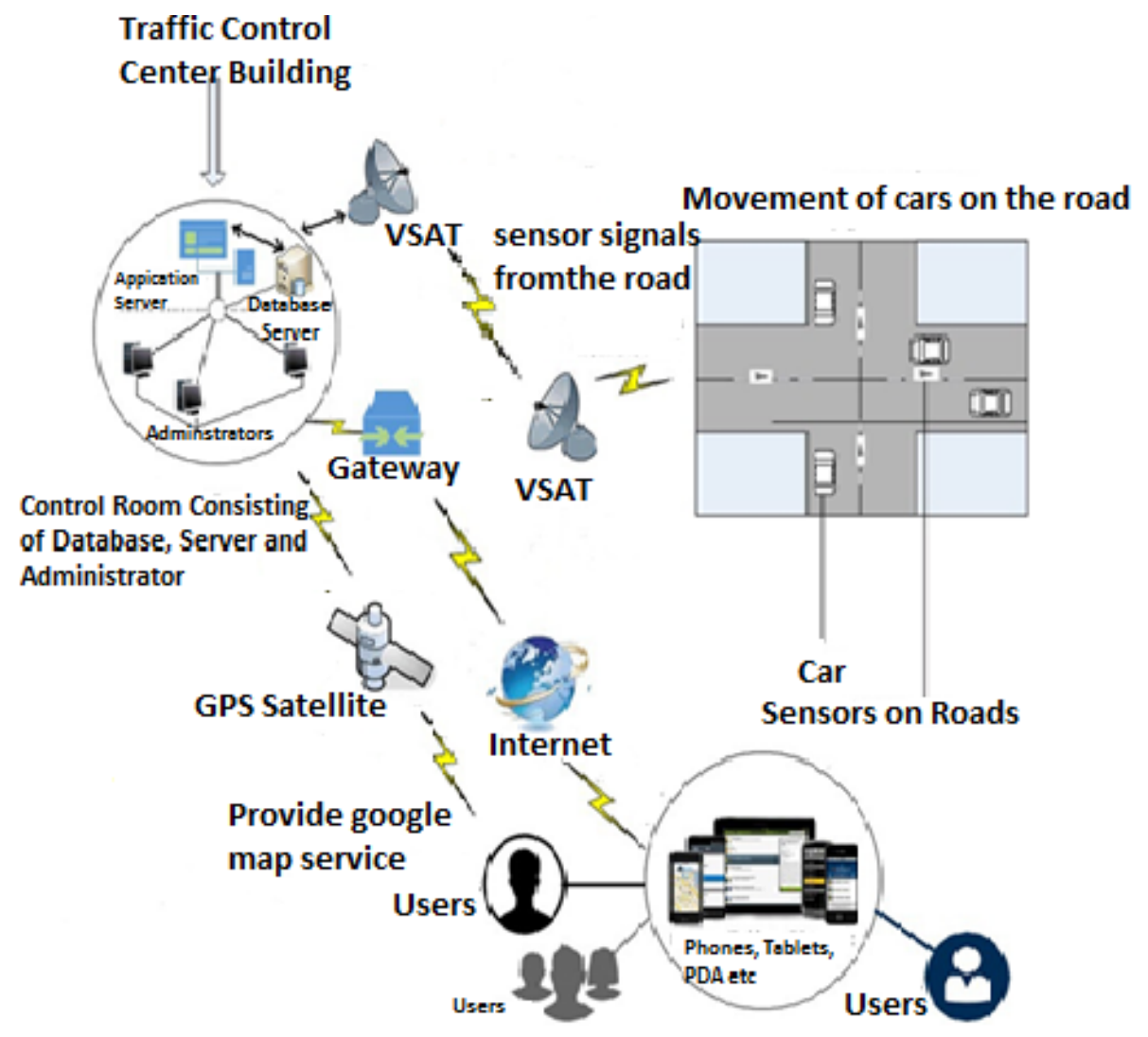

Fig. 1. Model Architecture for the intelligent traffic control system

Roads with appreciable distance from the traffic light junctions are equipped with weighted sensors and help to get information on the number of cars on the road. When the number of cars exceeds the benchmark, the sensors from the road send signals to the road VSAT. The VSAT on the road send the received signal to the control room via the control room VSAT. The GPS Satellite located in space provides road update information to the Google map. The control room consists of an application server, database server and system administrators which monitor traffic information. The information in the control room is being use to disseminate traffic information to mobile devices. The signal sent from the sensors is been processed in the control room then check its database if alternative routes are available. If alternative routes are found in the database, the control room uses a gateway to connect to the internet which then makes use of the Google map application located on the mobile device to relay the information in the form of a notification showing the message "Road is congested, Please take the alternative route". The system provides the list of alternative routes. 


\subsection{Simulation Model for the Mobile Traffic Management System}

In this research work, Netcracker 4.1 professional was used to simulate the proposed design. The simulation model using NetCracker simulator is shown in Figure 2. It depicts an intelligent traffic control system with appropriate connections from the sensor location to the network operations center (NOC). If a route is congested, the sensor node sends signals to the NOC (which contains the workgroup) where the signals are sent to be processed in the Alternative route processing center to check for alternative routes and when the route is found, it is then sent to the mobile device notifying car users of the alternative route.

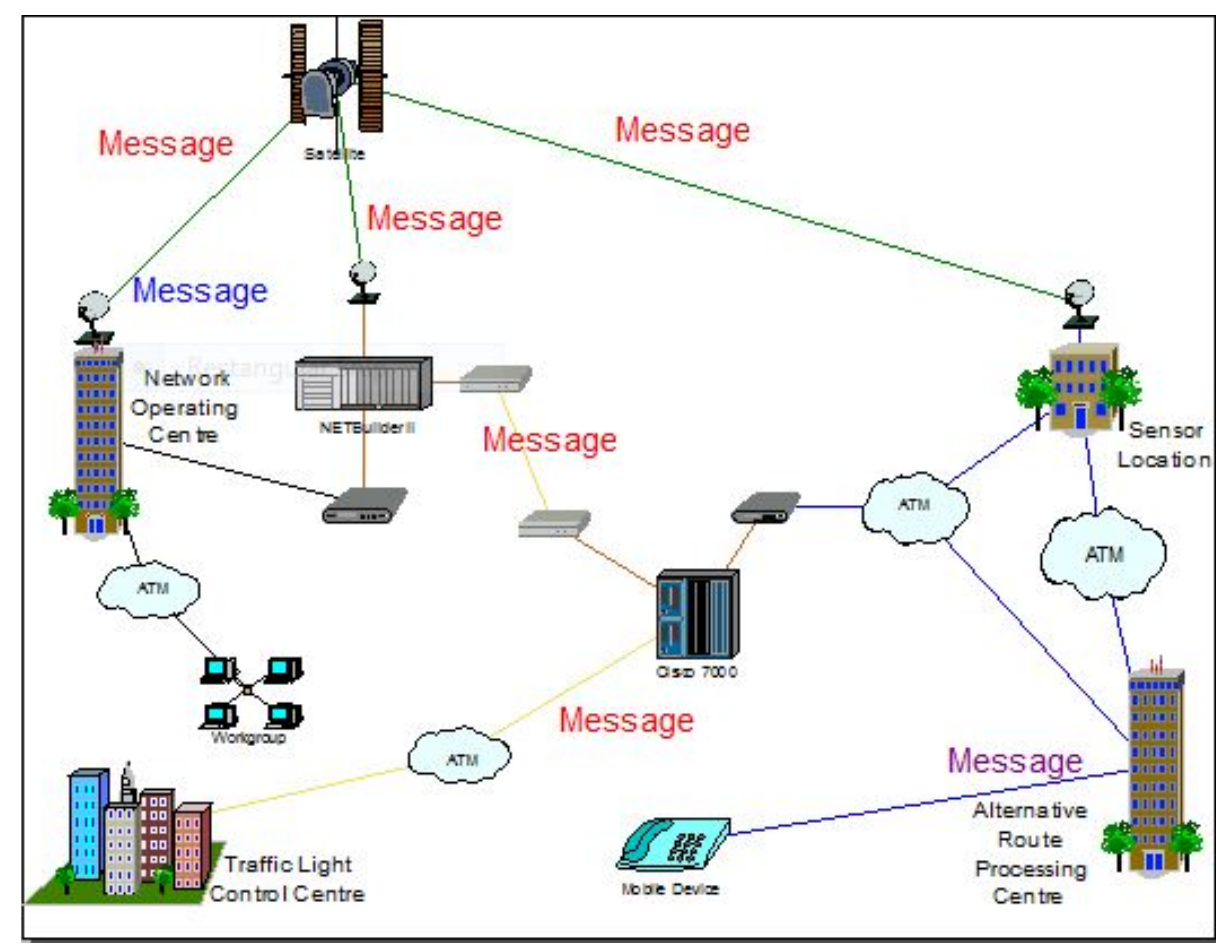

Fig. 2. Netcracker Simulation Interface for the Traffic Network

\subsection{Parameters Used In Evaluating the Performance of the Network}

Throughput: Throughput is the average data rate of successful data or message delivery over a specific communications link. It is controlled by available bandwidth, as well as the available signal-to-noise ratio and hardware limitations.

Throughput $(\mathrm{kb} / \mathrm{sec})=$ Window size $(\mathrm{kb}) /$ Delay time $(\mathrm{s})$. Where window size is the packet size and Delay time; is the lag time between the point when packets were sent and the point when it is being received.

Delay: The total time that it takes for a packet, to travel end-to-end is called network delay. Delay is measured in seconds. The delay of a network specifies how long 
it takes for a bit of data to travel across the network from one node or endpoint to another. It is typically measured in multiples or fractions of seconds.

Response time: Response time is the speed at which it takes a packet to be sent from a source to a destination. Response time is measured in seconds. The response time specifies how fast it takes for a packet sent from a source to get to its destination.

\subsection{The Database Design}

The database design shows different nodes that are attached to specific routes. A route consists of different paths and each path is divided by junctions called nodes and specified by path index in the database. The database - containing excerpt of traffic data within Lagos metropolis, Nigeria - also captures the latitude and longitude of the different nodes. For Route 1 the alternative routes are routes 2 and 3 . For route 2 the alternative routes are routes 1 and 3 and for route 3, the alternative routes are route 1 and 2. Table 1 shows the status of different nodes at different times. The node column contains a pointer to the Node in the node table, the day the status was retrieved, time in $24 \mathrm{hr}$ format and the status, which is the weight, returned from the weight sensors. A status of 1 indicates that the route is free while 6 indicate it is blocked. A seven-day history is kept for record purposes. Table 2 shows the different available routes in the database. Three routes that were considered for testing the application are:

Route 1: Allen Round About, Ikeja, Lagos, Nigeria - Kudirat Abiola Way, Ikeja, Lagos, Nigeria - Ikorodu Rd, Lagos, Nigeria - Mariland Bus Stop, Kosofe, Lagos, Nigeria.

Route 2: Allen Round About, Ikeja, Lagos, Nigeria - Ikeja Roundabout, Ikeja, Nigeria - Mobolaji Bank Anthony Way, Nigeria - Mariland Bus Stop, Kosofe, Lagos, Nigeria.

Route 3: Allen Round About, Ikeja, Lagos, Nigeria - Sheraton Link Rd. Ikeja, Nigeria - Mobolaji Bank Anthony Way, Nigeria - Mariland Bus Stop, Kosofe, Lagos, Nigeria.

For the application runs, junctions on the three routes are randomly assigned weights between one and six, with one indicating that the junction is free and six indicating that it is blocked. 
Table 1. Route status in the database

\begin{tabular}{|c|c|l|c|c|}
\hline -id & Node & \multicolumn{1}{|c|}{ Day } & Time & Status \\
\hline Filter & Filter & \multicolumn{1}{|c|}{ Filter } & Filter & Filter \\
\hline 7 & 2 & Friday & 13 & 4 \\
\hline 8 & 2 & Friday & 14 & 3 \\
\hline 9 & 2 & Friday & 15 & 3 \\
\hline 10 & 2 & Friday & 16 & 4 \\
\hline 11 & 2 & Friday & 17 & 5 \\
\hline 12 & 2 & Friday & 18 & 6 \\
\hline 13 & 2 & Friday & 19 & 6 \\
\hline 14 & 2 & Friday & 20 & 4 \\
\hline 15 & 2 & Saturday & 8 & 1 \\
\hline 16 & 2 & Saturday & 9 & 1 \\
\hline 17 & 2 & Saturday & 10 & 2 \\
\hline 18 & 2 & Saturday & 11 & 3 \\
\hline
\end{tabular}

Table 2. Different Available Routes in the Database

\begin{tabular}{|c|c|c|c|c|c|c|}
\hline id & Name & Lat & Long & Route & Path & Pathindex \\
\hline Filter & Filter & Filter & Filter & Filter & Filter & Filter \\
\hline 1 & $\begin{array}{l}\text { Allen Round } \\
\text { About,Ikeja,Lagos, Nigeria }\end{array}$ & 6507113 & 3348897 & $\begin{array}{l}\text { Ikeja to } \\
\text { Maryland }\end{array}$ & 1 & 0 \\
\hline 2 & $\begin{array}{l}\text { Kudirat Abiola Way, Ikeja } \\
\text { Lagos Nigeria }\end{array}$ & 6609692 & 335292 & $\begin{array}{l}\text { Ikeja to } \\
\text { Maryland }\end{array}$ & 1 & 2 \\
\hline 5 & Ikorodu Rd,Lagos Nigeria & 6588192 & 3378908 & $\begin{array}{l}\text { Ikeja to } \\
\text { Maryland }\end{array}$ & 1 & 3 \\
\hline 6 & $\begin{array}{l}\text { Mariland Bus Stop, Kosofe } \\
\text { Lagos Nigeria }\end{array}$ & 6571725 & 3367395 & $\begin{array}{l}\text { Ikeja to } \\
\text { Maryland }\end{array}$ & 1 & 4 \\
\hline 7 & $\begin{array}{l}\text { Allen Round } \\
\text { About,Ikeja,Lagos, Nigeria }\end{array}$ & 6607113 & 3348897 & $\begin{array}{l}\text { Ikeja to } \\
\text { Maryland }\end{array}$ & 2 & 0 \\
\hline 8 & $\begin{array}{l}\text { Ikeja Round } \\
\text { About,Ikeja,Lagos, Nigeria }\end{array}$ & 6597156 & 3341153 & $\begin{array}{l}\text { Ikeja to } \\
\text { Maryland }\end{array}$ & 2 & 1 \\
\hline 9 & $\begin{array}{l}\text { Mobolaji bank Anthony Ikeja } \\
\text { Nigeria }\end{array}$ & 6592674 & 3342827 & $\begin{array}{l}\text { Ikeja to } \\
\text { Maryland }\end{array}$ & 2 & 2 \\
\hline 10 & $\begin{array}{l}\text { Mariland Bus Stop, Kosofe } \\
\text { Lagos Nigeria }\end{array}$ & 6571725 & 3367395 & $\begin{array}{l}\text { Ikeja to } \\
\text { Maryland }\end{array}$ & 2 & 3 \\
\hline 11 & $\begin{array}{l}\text { Allen Round } \\
\text { About,Ikeja,Lagos, Nigeria }\end{array}$ & 6507055 & 3348958 & $\begin{array}{l}\text { Ikeja to } \\
\text { Maryland }\end{array}$ & 3 & 0 \\
\hline 12 & $\begin{array}{l}\text { Sheraton Link Ikeja,Lagos, } \\
\text { Nigeria }\end{array}$ & 6586165 & 3363849 & $\begin{array}{l}\text { Ikeja to } \\
\text { Maryland }\end{array}$ & 3 & 1 \\
\hline 13 & $\begin{array}{l}\text { Mobolaji bank Anthony Ikeja } \\
\text { Nigeria }\end{array}$ & 6583863 & 3358453 & $\begin{array}{l}\text { Ikeja to } \\
\text { Maryland }\end{array}$ & 3 & 2 \\
\hline 14 & $\begin{array}{l}\text { Mariland Bus Stop, Kosofe } \\
\text { Lagos Nigeria }\end{array}$ & 6571725 & 3367395 & $\begin{array}{l}\text { Ikeja to } \\
\text { Maryland }\end{array}$ & 3 & 3 \\
\hline
\end{tabular}




\subsection{Prototype Android Application (Mobile Route)}

The system design was illustrated using flowchart in Figure 3. The flowchart shows the coding process indicating the various conditions that govern the operation. An Android application called "MOBILE ROUTE" was developed for the implementation. The application is simply selected from list of installed apps on a mobile device. Ikeja, Lagos, Nigeria environment was used for the case study. The application simulates and selects the fastest route from one of three routes from the popular Ikeja roundabout to Maryland bus stop in Lagos. The application has a mobile route on the home page, where users are given access to simulate fastest route from ikeja to Maryland. Figure 4 is the traffic alert pop-up, which always alerts road users of the traffic situation on the road and also provides an alternative route. The information needed for getting the alternative routes is gathered from Figure 5, which shows the different available routes.

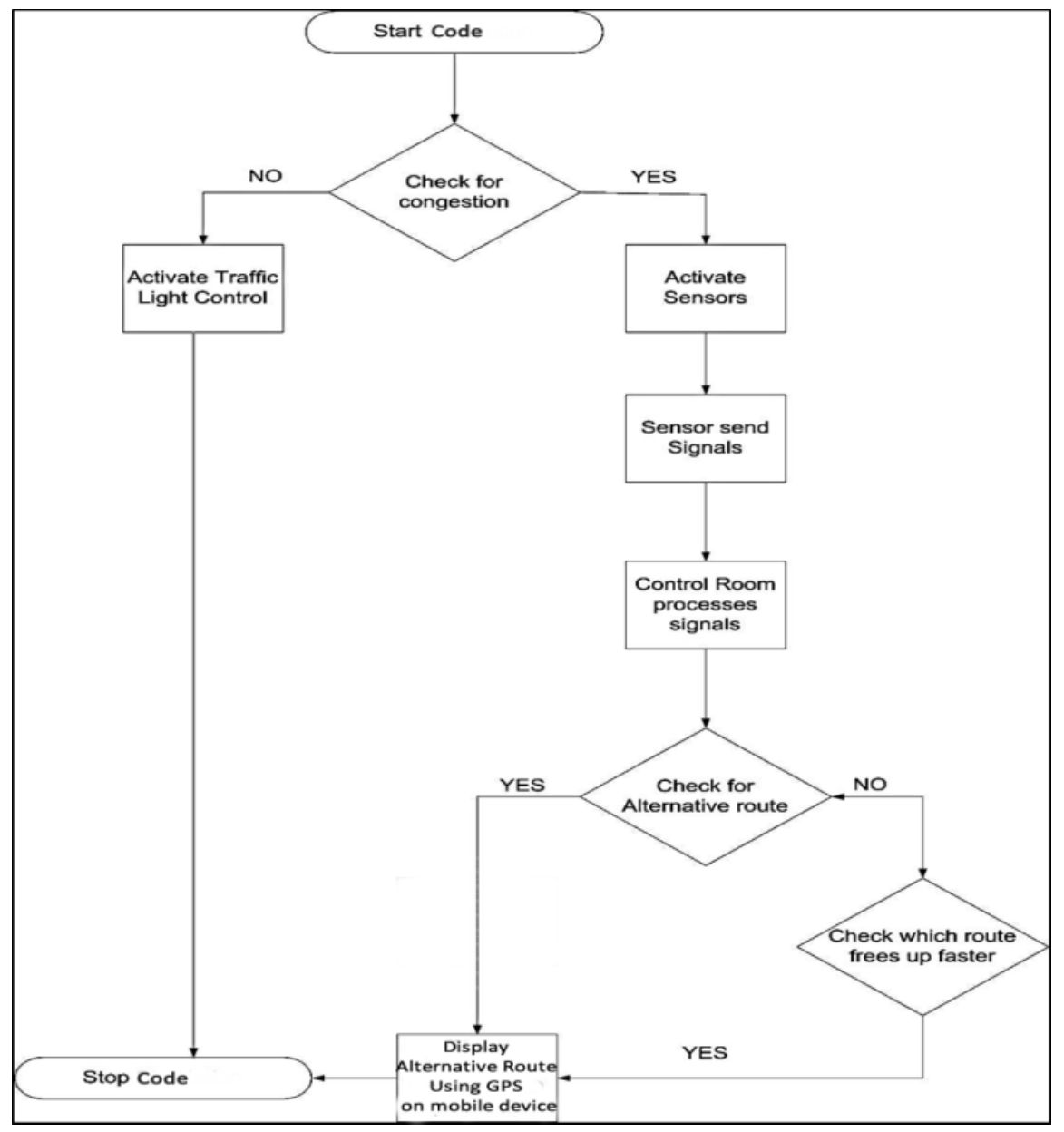

Fig. 3. Flowchart for the proposed traffic management system 


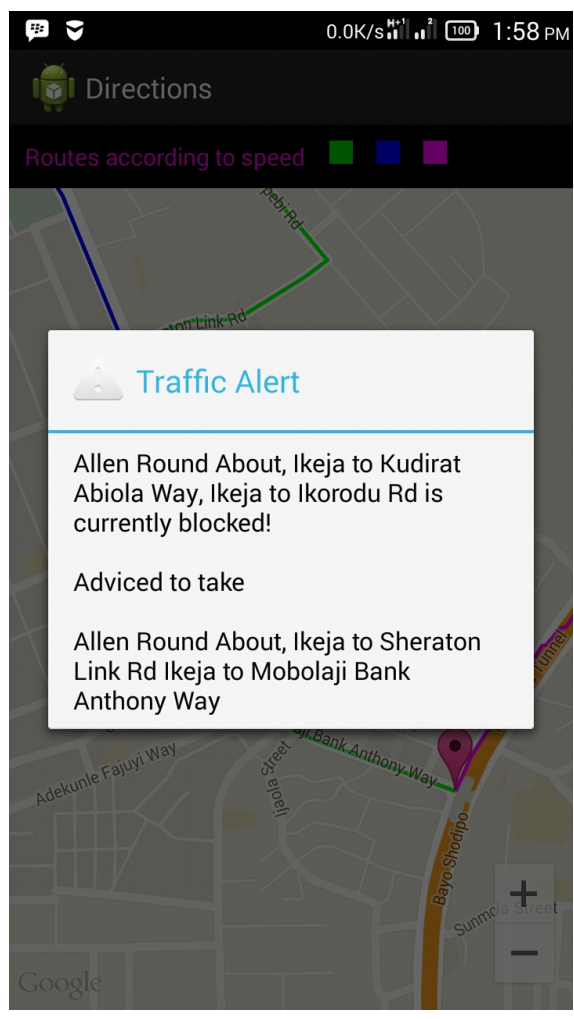

Fig. 4. Traffic Alert Pop-Up

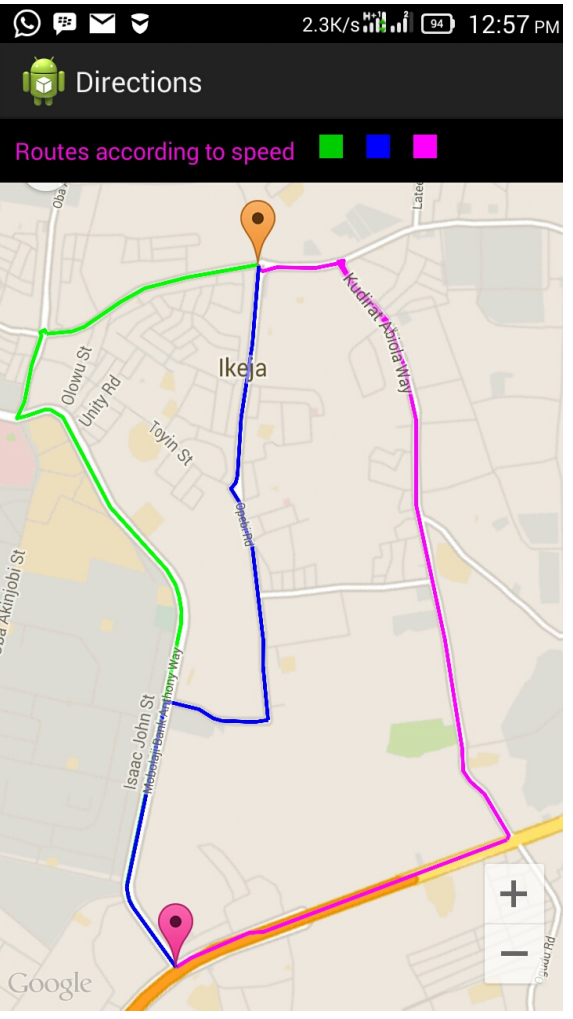

Fig. 5. Different Available Routes

Legend:

: Fastest route

Second fastest route

Slowest route

\section{Simulation Result And Discussion}

Figure 6 shows the various locations and their respective throughput, measured in bits/sec. It shows the values of the respective delay and window size of the various locations. It depicts that the mobile device uses lesser bandwidth than the traffic light center. This implies lower cost, in terms of throughputs, of communicating traffic information on mobile phones. The various locations and values of their respective delay time were shown in Figure 7. Simulation results showed that the delay between the Mobile Device and Traffic Light are very close, this implies that there the time wasted for the traffic information to be passed on to the road users is small. The response time for each location, measured in seconds, is shown in Figure 8. It was ob- 
served that mobile devices have the faster response time of 2.7 seconds than the Traffic Light Centre which has a response time of 50.1 seconds. This indicates that the mobile devices responds faster than the traffic light center and that, traffic information is arrive faster on the mobile devices.

\section{Throughput(B/S)}

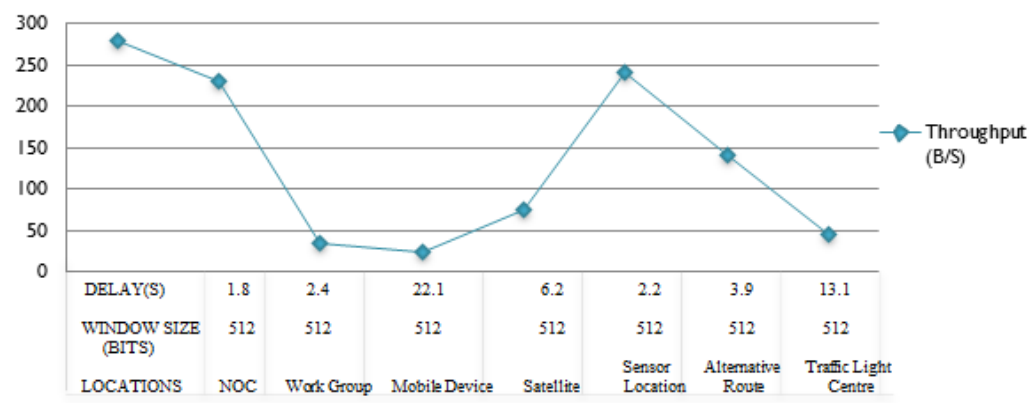

Fig. 6. Graph depicting the throughput of the locations in the network

\section{DELAY (S)}

Delay

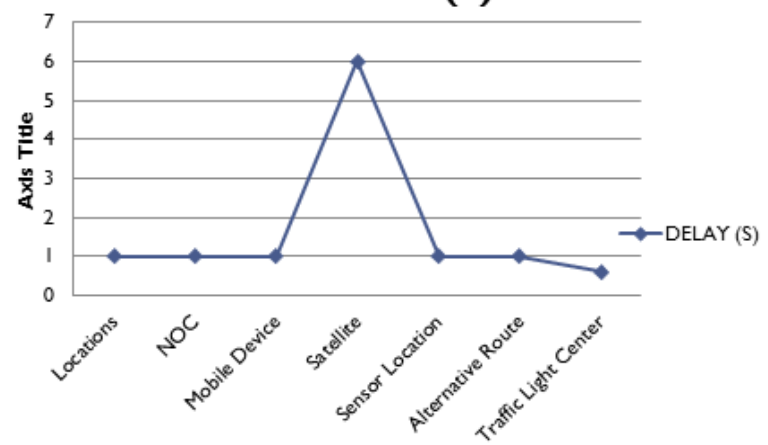

Fig. 7. Graph depicting the delay time of the locations of the network

\section{Response Time(S)}

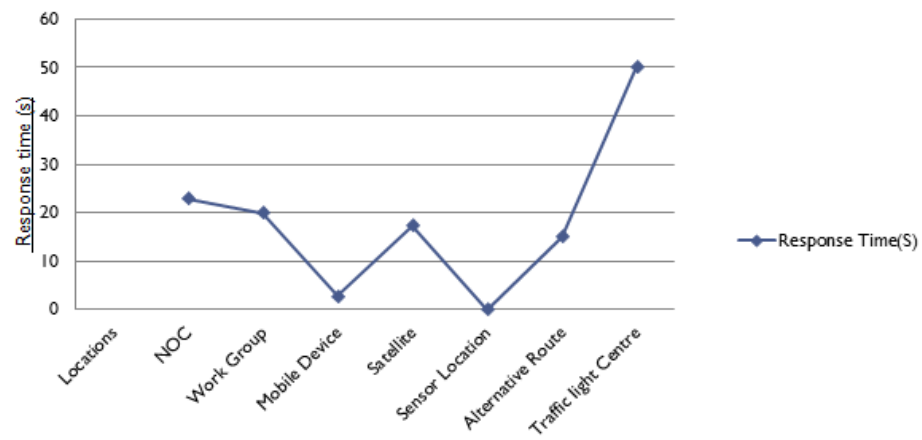

Fig. 8. Graph depicting the Response time of the locations of the network 


\section{Conclusion}

African countries have a very high dependency on satellites, with the majority of the countries having more than $95 \%$ of their international traffic carried by satellite ([17], [18], [19]). With almost all of Africa's international bandwidth provided by satellite, there is great potential for technologies such as VSAT to solve traffic problems in developing countries, although the lack of funds, expertise, equipment or awareness has contributed to developing countries not using satellite technology to its full potential [19]. In this research, we have been able to develop a model and create an application called "Mobile Route" to simulate and show different available routes ranked based on their probability of being traffic free. A traffic management system in which traffic updates are received on mobile devices based on information gotten from weighted sensors is capable of providing feasible alternative to the existing predetermined fixed based traffic control system, especially in developing countries, by reducing road congestion, long hours spent on the road, and creating more access routes at intervals when there is congestion in the road network. Reducing or eliminating congestion will lead to a better work-life balance, increase human productivity and help the economy to develop.

\section{$6 \quad$ References}

[1] Mohammad, J. \& Nasser, G. (2011), “A Fuzzy Reputation System in Vehicular Ad hoc Networks" Workshop on Emerging Topics in sensor networks. Available online at www.sciencedirect.com.

[2] Kang, W. Lee, J. Jeong, Y, Park, J. (2015) "VCC-SSF: Service-Oriented Security Framework for Vehicular Cloud Computing" Sustainability vol. 7, 2028-2044 www.mdpi.com/journal/sustainability. https://doi.org/10.3390/su7022028

[3] Niu, S. Zhang, J. Zhang, F Honghai, L. (2015) "A Method of UAVs Route Optimization Based on the Structure of the Highway Network". International Journal of Distributed Sensor Networks. Volume 20(2), 7 pages.

[4] Safdar, M. (2015) "Remote Sensing: A Mobile Vehicle Weight Sensor and its Application in Transportation (Case Study: Municipal Solid Waste Collection Vehicles)" 1st international Electronic Conference on Remote Sensing 22 June - 5 July.

[5] Mario, C. Tullio, G. Giovanni, P. \& Gianfranco, S. (2014), "Smart Traffic Light Junction Management Using Wireless Sensor Networks". Journal of WSEAS transactions on communications Vol. 13, pp $45-56$

[6] Javed, A. and Pandey, M. (2014), "Development of Intelligent Traffic Light System Based on Congestion Estimation Using Fuzzy Logic". Journal of Computer Engineering (IOSRJCE) Vol. 16( 3), pp 36-44.

[7] Viswanathan, V. and Santhanam, V. (2013), "Intelligent Traffic Signal Control Using Wireless Sensor Networks". Proceedings of the $2^{\text {nd }}$ International Conference on Advances in Electrical and Electronics Engineering (ICAEE'2013), March 17-18.

[8] Hussian, S. and Vinita, S. (2013), "Automated Intelligent Traffic Control System Using Sensors". International Journal of Soft Computing and Engineering (IJSCE). Vol, 3, pp 77 -85 . 
[9] Shruthi, k. and Vinodha, K. (2012), "Priority based traffic lights controller using wireless sensor networks". International Journal of Electronics Signals and Systems (IJESS), Vol. 3(4), pp $20-32$.

[10] Niittymaki, J. (2001) "Installation and Experience of Field Testing a Fuzzy Signal Controller". European Journal of Operation Research, Vol. 31, pp. 273-281. https://doi.org/10.1016/S0377-2217(00)00127-2

[11] Sheraz, S. Abbas, S. and Noor, H (2009), "Fuzzy Rule Based Traffic Signal Control System for Oversaturated Intersections". International Conference on Computational Intelligence and Natural Computing, vol. 2, pp.162-169.

[12] Al-Khateeb, K. Johari, J. and Wajdi. F (2008), "Dynamic Traffic Light Sequence Algorithm using RFID”. Journal of Computer Science, Vol. 5(2) pp 517-524.

[13] Dong, L. \& Chen, W (2010) "Real Time Traffic Signal for Urban Road MultiIntersection" Intelligent Information Management journal, 2010, Vol. 2, pp83-86. https://doi.org/10.4236/iim.2010.28058

[14] Hafizah Binti Ka'ab (2010), "Development of intelligent traffic light control using fuzzy logic" A thesis submitted for the award of bachelor of Electronic Engineering (Computer Engineering) Faculty of Electronic and Computer Engineering. University Teknikal Malaysia Melaka April, 2010.

[15] Commission of the European Communities (2009)," Traffic Management for Land Transport" Transport Research Knowledge Centre website at www.transportresearch.info/web/projects/transport_themes.cfm

[16] Michel dos Santos Soares, Jos Vrancken, Yubin Wang (2010)," Architecture-Based Development of Road Traffic Management Systems" in proc.2010 IEEE International Conference on Networking,Sensing and Control,Chicago,IL, USA, April 10-12,2010,pages 26$31,2010$.

[17] Moroney, S., Hamilton, P., \& Africa, A. I. T. E. C. (2004). Satellite and VSAT: Innovative uses for Rural Telephony and Internet Development.

[18] Nielinger, O. (2004). Assessing a decade of liberal sector reforms in African telecommunications. Report, Institute of African Affairs, Hamburg.

[19] Wood, D. R. (2008). The use of satellite-based technology in developing countries (Doctoral dissertation, Massachusetts Institute of Technology).

\section{$7 \quad$ Authors}

Akinboro Solomon A. (principal and corresponding author) a Senior Lecturer from Bells University of Technology, Ota, Ogun state, Nigeria, holds a B. Tech degree in Computer Engineering from Ladoke Akintola University of Technology, Ogbomosho, M.Sc. and $\mathrm{PhD}$ in Computer science from Obafemi Awolowo University Ile-Ife. Research interests include Distributed system and computer network, Mobile Computing and Machine Learning. Member of the following professional bodies: Nigeria Computer Society, Nigeria Society of Engineers and Council for the Regulation of Engineering in Nigeria (akinboro2002@yahoo.com)

Adeyiga Johnson holds a Bachelor of Science (BS.c) degree and Master of Science (MS.c) degree in Computer Science both from the University of Ibadan. He is a member of the computer professional registration council of Nigeria, a computer scientist with specialty in cybercrime and mobile computing. He currently lecture in 
Bells University of Technology, Ota, Ogun state, Nigeria.He has taught many courses in computer science and supervised many projects.

Adebayo Omotosho received his $\mathrm{PhD}$ in Computer Science at Ladoke Akintola University of Technology in 2016. He is a Seasoned Computer Programmer and has taken part in a number of programming competitions in $\mathrm{C} / \mathrm{C}++/ \mathrm{C} \#$. He is a member of the Nigeria Computer Society (NCS), Computer Professional [Registration Council] of Nigeria (CPN), Computer Science Teachers Association for Computing Machinery (ACM), and International Association of Computer Science and Information Technology. His research interests are health informatics, computer security, machine learning and biometrics.

Akinwale O. Akinwunmi is a Phd holder and lecturer at the Department of Computer Science and Information Technology, Bowen University, Iwo, Osun State. Nigeria. He is an Assistant Director, Information and Communication Technology (ICT) Directorate of the same University. His research interest among others includes Networking and Communication, Hardware, Distributed Systems, Mobile Computing, Modelling and Simulation(Phone: 2348034237441 E-mail: walebunmi@gmail.com ).

Article submitted 08 February 2017. Published as resubmitted by the authors 16 April 2017. 